Supporting Information for:

\title{
Employing Forbidden Transitions as Qubits in a Nuclear Spin-Free Chromium Complex
}

Majed S. Fataftah, Joseph M. Zadrozny, Scott C. Coste, Michael J. Graham, Dylan M. Rogers, and Danna E. Freedman*

Department of Chemistry, Northwestern University, Evanston, Illinois 60208-3113

J. Am. Chem. Soc. 


\section{Table of Contents:}

$\begin{array}{ll}\text { Experimental Details } & \text { S3 }\end{array}$

$\begin{array}{ll}\text { Table S1: Crystallographic information of } \mathbf{1 .} & \text { S8 }\end{array}$

Table S2: Crystallographic information of $2 . \quad$ S9

Figure S1: Thermal ellipsoid plots of 1 and $2 . \quad 510$

Figure S2: Magnetic susceptibility of 1 under 1000 Oe dc field. $\quad$ S11

Figure S3: Variable field, variable temperature magnetization of 1. $\quad$ S12

Figure S4: $51.6 \mathrm{GHz}$ cw-EPR spectrum for 1 at $5 \mathrm{~K}$ S13

Figure S5: Zeeman diagrams for observed 51.6 GHz EPR transitions. $\quad$ S14

Figure S6: Echo-detected field-sweep of 1' at X-band frequency. $\quad$ S15

Figure S7: Variable temperature echo decay intensity of 1' at $3500 \mathrm{G}$ S16

$\begin{array}{ll}\text { Figure S8: } T_{2} \text { versus temperature for } \mathbf{1}^{\prime} \text { at } 3500 \mathrm{G} . & \text { S17 }\end{array}$

Figure S9: Variable temperature inversion-recovery of 1' at 3500 G. $\quad$ S18

$\begin{array}{ll}\text { Figure S10: Temperature versus } T_{1} \text { of } \mathbf{1}^{\prime} . & \text { S19 }\end{array}$

Figure S11: Inversion-recovery data for 1' at $1000 \mathrm{G}$ and $5 \mathrm{~K} . \quad$ S20

Figure S12: Overlay of variable power nutations of 1' at $3500 \mathrm{G}$ S21

Figure S13: Fast Fourier Transforms of variable power nutations of 1' at $3500 \mathrm{G} . \quad$ S22

Figure S14: Overlay of variable power nutations of 1' at $1000 \mathrm{G}$ S23

Figure S15: Fits to variable power nutations of 1' at $1000 \mathrm{G}$. $\quad$ S24

Figure S16: Fast Fourier Transforms of $T_{2}$ data of $\mathbf{1}^{\prime}$ at $3500 \mathrm{G}$.

$\begin{array}{ll}\text { References } & \text { S26 }\end{array}$ 


\section{Experimental Details.}

General Considerations. Manipulations of all compounds were performed under a dinitrogen atmosphere in a Vacuum Atmospheres Nexus II glovebox. Glassware was either oven-dried at $150{ }^{\circ} \mathrm{C}$ for at least 4 hours or flame-dried prior to use. Acetonitrile $(\mathrm{MeCN})$, diethylether $\left(\mathrm{Et}_{2} \mathrm{O}\right)$, methanol $(\mathrm{MeOH})$, and toluene were dried using a commercial solvent purification system from Pure Process Technology and stored over 3 or $4 \AA$ sieves prior to use. Butyronitrile (BuCN) was dried by distilling over $\mathrm{CaH}_{2}$ and stored over $4 \AA$ sieves. All solvents were degassed by three successive freeze-pump-thaw cycles and filtered through a pad of activated alumina. Deuterated $\mathrm{MeCN}$ and toluene were purchased from Cambridge Isotope Labs, deoxygenated by three successive freeze-pump-thaw cycles, filtered through a pad of activated alumina, and stored over $4 \AA$ sieves prior to use. $\mathrm{CrCl}_{3} \cdot 3 \mathrm{THF}$ was prepared from $\mathrm{CrCl}_{3} \cdot 6 \mathrm{H}_{2} \mathrm{O}$ by reaction with trimethylsilyl chloride in THF. ${ }^{1}$ 4,5-bis(benzoylthio)1,3-dithiole-2-thione (benzoyl dmit) was prepared by the literature methods. ${ }^{2}$ The deuterated counterion, $\mathrm{d}_{20}-\mathrm{Ph}_{4} \mathrm{PBr}$, was synthesized according to previously reported procedure. ${ }^{3,4}$ All other chemicals were used as received.

$\left(\mathbf{P h}_{4} \mathbf{P}\right)_{3}\left[\mathbf{G a}\left(\mathbf{C}_{3} \mathbf{S}_{5}\right)_{3}\right]$ (2). NaOMe $(333 \mathrm{mg}, 5.92 \mathrm{mmol})$ was combined with benzoyl dmit (1.2 g, $2.95 \mathrm{mmol}$ ) in $10 \mathrm{~mL}$ of $\mathrm{MeOH}$ and was allowed to stir for an hour giving a dark red solution, to which $\mathrm{Ga}\left(\mathrm{NO}_{3}\right)_{3}(260 \mathrm{mg}, 1.02 \mathrm{mmol})$ was added and allowed to stir over night. A solution of $\left(\mathrm{Ph}_{4} \mathrm{P}\right) \mathrm{Br}(1.2 \mathrm{~g}, 2.95 \mathrm{mmol})$ in $2 \mathrm{~mL}$ of $\mathrm{MeOH}$ was added dropwise leading to the formation of a red precipitate. The mixture was stirred for an additional hour, after which the volume was reduced by half under vacuum. To this solution, $5 \mathrm{~mL}$ of $\mathrm{Et}_{2} \mathrm{O}$ was then added and the solution 
was allowed to sit in the freezer at $-35{ }^{\circ} \mathrm{C}$ overnight. The solution was then filtered and the red solid was washed with $10 \mathrm{~mL}$ of $\mathrm{Et}_{2} \mathrm{O}$. The collected solid was redissolved in approximately 20 $\mathrm{mL}$ hot $\mathrm{MeCN}$, filtered through diatomaceous earth, and $\mathrm{Et}_{2} \mathrm{O}$ was slowly diffused into the solution to produce dark red plates $(655 \mathrm{mg}, 38.7 \%)$ suitable for X-ray diffraction. IR $\left(\mathrm{cm}^{-1}\right)$ : 3078(w), 3042(w), 3014(w), 2986(w), 1584(s), 1482(s), 1434(vs), 1410(vs), 1338(m), 1314(m), 1187(m), 1163(m), 1107(vs), 1055(s), 1033(vs), 994(vs), 977(w), 903(w), 888(m), 850(w), 838(w), 754(s), 718(vs), 685(vs), 615(w), and 521(vs). UV-vis (MeCN); $v_{\max }\left(\varepsilon_{\mathrm{M}}, \mathrm{M}^{-1} \mathrm{~cm}^{-1}\right): 500$ (1370) $\mathrm{nm}$ and 445 (3320) nm. ${ }^{1} \mathrm{H}$ NMR (400 MHz, $\left.\mathrm{CDCl}_{3}, 298 \mathrm{~K}\right): \delta 7.83(\mathrm{~m}, 1 \mathrm{H}), 7.73(\mathrm{~m}$, 2H), $7.62(\mathrm{~m}, 2 \mathrm{H}) \mathrm{ppm} .{ }^{13} \mathrm{C} \mathrm{NMR}\left(400 \mathrm{MHz}, \mathrm{CDCl}_{3}, 298 \mathrm{~K}\right): \delta 208.11,137.33,135.57,135.54$, 134.54, 134.44, 130.68, 130.56, 117.86, 116.97, 1.88 ppm. Anal. Calcd. for $\mathrm{C}_{81} \mathrm{H}_{40} \mathrm{P}_{3} \mathrm{~S}_{15} \mathrm{Ga}$ : $58.67 \%$ C; $2.41 \%$ H. Found: $58.32 \% \mathrm{C} ; 2.27 \% \mathrm{H}$.

$\left(\mathbf{d}_{20}-\mathbf{P h}_{4} \mathbf{P}\right) \cdot \mathbf{1}$ and $\left(\mathbf{d}_{20}-\mathbf{P h} \mathbf{h}_{4} \mathbf{P}\right) \cdot \mathbf{2}$ were synthesized by the same procedure as their protiated counterparts, $\mathbf{1}$ and $\mathbf{2}$ with $\mathrm{d}_{20}-\mathrm{Ph}_{4} \mathrm{P}^{+}$as the counterion.

$\left(\mathbf{d}_{20}-\mathbf{P h}_{4} \mathbf{P}\right)_{3}\left[\mathbf{C r}_{0.01} \mathbf{G a}_{0.99}\left(\mathbf{C}_{3} \mathbf{S}_{5}\right)_{3}\right]\left(\mathbf{1}^{\prime}\right) .1 .0 \mathrm{mg}$ of $\left(\mathbf{d}_{20}-\mathbf{P h}_{4} \mathbf{P}\right) \cdot \mathbf{1}$ was dissolved with $96.1 \mathrm{mg}$ of $\left(\mathbf{d}_{20}-\mathbf{P h}_{4} \mathbf{P}\right) \cdot \mathbf{2}$ in $10 \mathrm{~mL}$ of $\mathrm{MeCN}$ and $100 \mathrm{~mL}$ of $\mathrm{Et}_{2} \mathrm{O}$ was added over the course of two minutes to crash the product out as a red powder that was filtered and further washed with $\mathrm{Et}_{2} \mathrm{O}$.

Magnetic Measurements. Magnetic data were acquired on a Quantum Design MPMS-XL SQUID magnetometer. Measurements for $\mathbf{1}$ were obtained on finely ground microcrystalline powders restrained in a frozen eicosane matrix and either flame sealed in a quartz tube or wrapped tightly within a polyethylene bag. In the latter case, the sample was transferred to the SQUID under a flow of Ar gas. Dc susceptibility measurements were collected in the temperature range of 1.8-300 $\mathrm{K}$ at a dc field of 1000 Oe. Magnetization measurements were 
obtained in the temperature range $1.8-10 \mathrm{~K}$ under dc fields of $1,2,3,4,5,6$, and $7 \mathrm{~T}$. Dc magnetic susceptibility data were corrected for diamagnetic contributions from the sample holder and eicosane as well as for the core diamagnetism of each sample, estimated using Pascal's constants. ${ }^{5}$ Prior to full characterization, magnetization data were acquired at $100 \mathrm{~K}$ from 0 to 4 T to ensure the absence of curvature associated with ferromagnetic impurities.

X-ray Diffraction. Single crystal X-ray diffraction data were acquired on single crystals coated with Paratone-N oil and mounted on a MicroMounts ${ }^{\mathrm{TM}}$ rod. The crystals were frozen under a stream of $\mathrm{N}_{2}$ during measurements. Data were collected with a Bruker MICROSTAR X-ray source of Mo $\operatorname{K} \alpha(\lambda=0.71073 \AA)$ radiation and a Bruker APEX-II detector. Raw data were integrated and corrected for Lorentz and polarization effects using Bruker Apex2 v. 2013.2. Absorption corrections were applied using SADABS. ${ }^{6}$ Space group assignments were determined by examination of systematic absences, $E$-statistics, and successive refinement of the structures. The crystal structure was solved by direct methods with the aid of successive difference Fourier maps in SHELXL ${ }^{7}$ operated with the OLEX2 interface. ${ }^{8}$ The crystals did not show significant decay during data collection. Thermal parameters were refined anisotropically for all non-hydrogen atoms in the main body, solvents of crystallization, and counterions. Hydrogen atoms were placed in ideal positions and refined using a riding model for all structures.

EPR Spectroscopy. All measurements were conducted on samples prepared in an inert dinitrogen atmosphere and flame sealed under vacuum in a quartz tube. $\mathrm{Cw}$-EPR measurements at $51.6 \mathrm{GHz}$ were performed on an instrument described elsewhere. ${ }^{9}$ The $298 \mathrm{~K} \mathrm{X}$-band $(9.45$ GHz) cw EPR spectrum was collected on a $9.3 \mathrm{GHz}$ Bruker EleXsys E 500 spectrometer at the University of Chicago. Spectra were fit with the use of Easyspin ${ }^{10}$ employing the spin 
Hamiltonian used in the main report. Linewidths were modeled with $D$-strain, using 0.0378 and $0.0011 \mathrm{~cm}^{-1}$, respectively, for the $D$ and $E$ values obtained from the $51.6 \mathrm{GHz}$ spectrum. Simulation of the continuous wave X-band spectrum required deviation from a pure powder average and accounting for a fraction of the sample that was preferentially aligned along the $y$ axis of the molecule. $77 \mathrm{~K}$ Pulsed EPR measurements were performed at the National High Magnetic Field Laboratory (NHMFL) at X-band frequency $(9.715-9.737 \mathrm{GHz})$ on a Bruker E680 spectrometer equipped with an ER 4118X-MD5 dielectric resonator. Temperature was controlled using an Oxford Instruments CF935 helium flow cryostat and an Oxford Instruments ITC503 temperature controller. Pulsed measurements were performed on polycrystalline samples of $\mathbf{1}^{\prime}$ sealed in a quartz tube. Calibration of $B_{1}$ was performed using a dilute sample of $\alpha, \gamma-$ Bisdiphenylene- $\beta$-phenylallyl radical (BDPA, $g=2.00359$ ) at the observed transition (3460 G, $v$ $=9.7 \mathrm{GHz})$.

Echo-detected field-swept EPR spectra were collected using a two pulse Hahn-echo sequence using microwave pulses (mw) of 16 and $32 \mathrm{~ns}$ and an interpulse time $\tau=120 \mathrm{~ns} . T_{2}$ decay curves were collected with the same two pulse Hahn-echo sequence with mw pulses of 16 and $32 \mathrm{~ns}$ with varying $\tau$ starting from $120 \mathrm{~ns}$. Spin-lattice relaxation times $\left(T_{1}\right)$ were collected by application of a three-pulse inversion recovery sequence (32 ns $-\tau-16 \mathrm{~ns}-32 \mathrm{~ns}$ ) with time delay $(\tau)$ between the first two pulses up to $1 \mathrm{~ms}$. Transient nutations were collected using a three pulse sequence beginning with a variable length nutation (tipping) pulse $\left(t_{\mathrm{p}}\right)$ with the following sequence, $\left(t_{\mathrm{p}}-T-\tau-\pi^{\pi} / 2-\tau-\pi-\tau-\mathrm{echo}\right)$. The $t_{\mathrm{p}}$ was varied in $4 \mathrm{~ns}$ increments, with 16 and $32 \mathrm{~ns}$ pulses to follow. The delay time (T) was held constant at $5 \mu \mathrm{s}$, and $\tau$ was held constant at $120 \mathrm{~ns}$. Fast Fourier Transformation of the ESEEM and nutation data was performed with a Hamming window. All $T_{2}$ decay curves were fit using the following stretched exponential decay function, 
$I=I_{0} e^{-2 \tau / T_{2}{ }^{q}}$, where $I_{0}$ is the initial intensity, $2 \tau$ is the interpulse delay time, and $T_{2}$ is the coherence time, and $q$ the stretch factor. Nutation data were fit using the following function to extract the Rabi frequency, $I=I_{0} e^{-t_{p} / m} \cos \left(v t_{p}\right)$, where $m$ is the oscillation damping time, $v$ is the Rabi frequency, and $t_{\mathrm{p}}$ is the tipping pulse length. ${ }^{11}$

Deuteration of the $\mathrm{Ph}_{4} \mathrm{P}^{+}$counterion was necessary to eliminate the Hartmann-Hahn effect that prohibited clear investigation of the Rabi frequency dependence on $B_{1}$. In addition, hyperfine interactions with surrounding protons led to the observation of artificial peaks in the EDFS spectra, complicating assignment of transitions and thus measurements on $\mathbf{1}^{\prime}$ allowed a more careful investigation of complex $\mathbf{1}$ by pulsed EPR. The theoretically expected Rabi frequencies were calculated for the transitions using the equation ${ }^{12} \Omega_{\mathrm{R}}=$ $\frac{g B_{1} \mu_{\mathrm{B}}}{\hbar} \sqrt{S(S+1)-m_{S}\left(m_{S}+1\right)}$, and small deviations from the expected Rabi frequencies are due to mixing of the $M_{S}$ states at low magnetic fields for the transition at 3500 Oe. The expected Rabi frequency for the forbidden transition at 1000 Oe between the $M_{S}=-3 / 2$ and $M_{S}=+3 / 2$ states is expected to be lower than that of the allowed transition, and is evident from the $B_{1}$ dependence observed at X-band. ${ }^{8}$

All Other Physical Measurements. Combustion analyses of all complexes were performed by Midwest Microlab (Indianapolis, IN). Infrared spectra were recorded on a Bruker Alpha FTIR spectrometer equipped with an attenuated total reflectance accessory. Solution-phase NMR spectra were collected with a $400 \mathrm{MHz}$ Agilent DD MR-400 system equipped with Agilent 7600 96-sample autosampler. Proton NMR spectra are referenced to $\mathrm{CDCl}_{3}$ at $7.26 \mathrm{ppm}$. UV-vis spectra were collected on a Varian Cary 5000 spectrometer in MeCN and molar absorptivities $(\varepsilon)$ were calculated from single data points. 
Table S1. Crystallographic information for the structural refinement of $\mathbf{1 .}$

\begin{tabular}{ll}
\hline Empirical Formula & $\mathrm{C}_{81} \mathrm{H}_{40} \mathrm{P}_{3} \mathrm{~S}_{15} \mathrm{Cr}$ \\
Formula weight & $1659.10 \mathrm{~g} / \mathrm{mol}$ \\
Temperature & $100.0 \mathrm{~K}$ \\
Wavelength & $0.71073 \AA$ \\
Crystal System & Triclinic \\
Space Group & $P-1$ \\
Unit Cell Dimensions & $a=34.449(2) \AA, \alpha=90.0(0)^{\circ}$ \\
& $b=22.892(2) \AA, \beta=102.744(5)^{\circ}$ \\
& $c=23.2521(15) \AA, \gamma=90.0(0)^{\circ}$ \\
Volume & $17836(18) \AA^{3}$ \\
$Z$ & 8 \\
Density (calculated) & $1.232 \mathrm{Mg} / \mathrm{m}^{3}$ \\
Absorption coefficient & $0.571 \mathrm{~mm}^{-1}$ \\
$F_{\text {0oo }}$ & 6840.0 \\
Crystal color & Purple \\
Crystal size & $0.21 \cdot 0.19 \cdot 0.15 \mathrm{~mm}^{3}$ \\
$\theta$ range & 2.20 to $29.27^{\circ}$ \\
Index ranges & $-11 \leq h \leq 11$ \\
& $-20 \leq k \leq 20$ \\
Reflections collected & $-23 \leq l \leq 22$ \\
Independent reflections & 15218 \\
Completeness to $\theta=24.689^{\circ}$ & $15115\left[R_{\text {int }}=0.0539\right]$ \\
Absorption correction & $99.3 \%$ \\
Maximum and minimum transmission & Multi-scan \\
Refinement method & 0.971 and 0.809 \\
Data / restraints / parameters & Full-matrix least-squares on $\mathrm{F}^{2}$ \\
Goodness-of-fit on $\mathrm{F}^{2 a}$ & $11047 / 10 / 901$ \\
Final $R$ indices [I $>2 \sigma(\mathrm{I})=11047$ data $]^{b}$ & 0.9730 \\
$R$ indices (all data, $0.80 \AA)$ & $R_{1}=4.20 \%, w R_{2}=11.27 \%$ \\
Largest diff. peak and hole & $R_{1}=6.13 \%, w R_{2}=11.27 \%$ \\
\hline
\end{tabular}

${ }^{a} \mathrm{GooF}=\left[\Sigma\left[w\left(F_{\mathrm{o}}^{2}-F_{\mathrm{c}}{ }^{2}\right)^{2}\right] /(\mathrm{n}-\mathrm{p})\right]^{1 / 2}$ where $\mathrm{n}$ is the number of reflections and $\mathrm{p}$ is the total number of parameters refined. ${ }^{b} R_{1}=\Sigma|| F_{\mathrm{o}}|-| F_{\mathrm{c}} \| / \Sigma\left|F_{\mathrm{o}}\right| ; w R_{2}=\left[\Sigma\left[w\left({F_{\mathrm{o}}}^{2}-F_{\mathrm{c}}{ }^{2}{ }^{2}\right] / \Sigma\left[w\left(F_{\mathrm{o}}{ }^{2}\right)^{2}\right]\right]^{1 / 2}\right.$ 
Table S2. Crystallographic information for the structural refinement of $\mathbf{2}$.

\begin{tabular}{ll}
\hline Empirical Formula & $\mathrm{C}_{81} \mathrm{H}_{40} \mathrm{P}_{3} \mathrm{~S}_{15} \mathrm{Ga}$ \\
Formula weight & $1676.82 \mathrm{~g} / \mathrm{mol}$ \\
Temperature & $100(2) \mathrm{K}$ \\
Wavelength & $0.71073 \AA$ \\
Crystal System & Triclinic \\
Space Group & $P-1$ \\
Unit Cell Dimensions & $a=34.449(2) \AA, \alpha=90.0(0)^{\circ}$ \\
& $b=22.8748(14) \AA, \beta=103.133(3)^{\circ}$ \\
& $c=23.2685(13) \AA, \gamma=90.0(0)^{\circ}$ \\
Volume & $17836.5(18) \AA^{3}$ \\
$Z$ & 8 \\
Density (calculated) & $1.249 \mathrm{Mg} / \mathrm{m}^{3}$ \\
Absorption coefficient & $0.753 \mathrm{~mm}^{-1}$ \\
$F_{\text {0oo }}$ & 6896.0 \\
Crystal color & Purple \\
Crystal size & $0.14 \cdot 0.415 \cdot 0.547 \mathrm{~mm}^{3}$ \\
$\theta$ range & 2.20 to $29.27^{\circ}$ \\
Index ranges & $-11 \leq h \leq 11$ \\
& $-20 \leq k \leq 20$ \\
Reflections collected & $-23 \leq l \leq 22$ \\
Independent reflections & 21094 \\
Completeness to $\theta=29.27^{\circ}$ & $15982\left[R_{\text {int }}=3.14\right]$ \\
Absorption correction & $98.7 \%$ \\
Maximum and minimum transmission & Multi-scan \\
Refinement method & 0.893 and 0.835 \\
Data / restraints / parameters & Full-matrix least-squares on $\mathrm{F}^{2}$ \\
Goodness-of-fit on $\mathrm{F}^{2 a}$ & $10626 / 10 / 901$ \\
Final $R$ indices [I $>2 \sigma(\mathrm{I})=10626$ data $]^{b}$ & 1.1040 \\
$R$ indices (all data, $0.80 \AA$ A & $R_{1}=6.39 \%, w R_{2}=20.74 \%$ \\
Largest diff. peak and hole & $R_{1}=8.33 \%, w R_{2}=20.74 \%$ \\
\hline
\end{tabular}

${ }^{a} \mathrm{GooF}=\left[\Sigma\left[w\left(F_{\mathrm{o}}^{2}-F_{\mathrm{c}}{ }^{2}\right)^{2}\right] /(\mathrm{n}-\mathrm{p})\right]^{1 / 2}$ where $\mathrm{n}$ is the number of reflections and $\mathrm{p}$ is the total number of parameters refined. ${ }^{b} R_{1}=\Sigma|| F_{\mathrm{o}}|-| F_{\mathrm{c}} \| / \Sigma\left|F_{\mathrm{o}}\right| ; w R_{2}=\left[\Sigma\left[w\left({F_{\mathrm{o}}}^{2}-F_{\mathrm{c}}{ }^{2}{ }^{2}\right] / \Sigma\left[w\left(F_{\mathrm{o}}{ }^{2}\right)^{2}\right]\right]^{1 / 2}\right.$ 


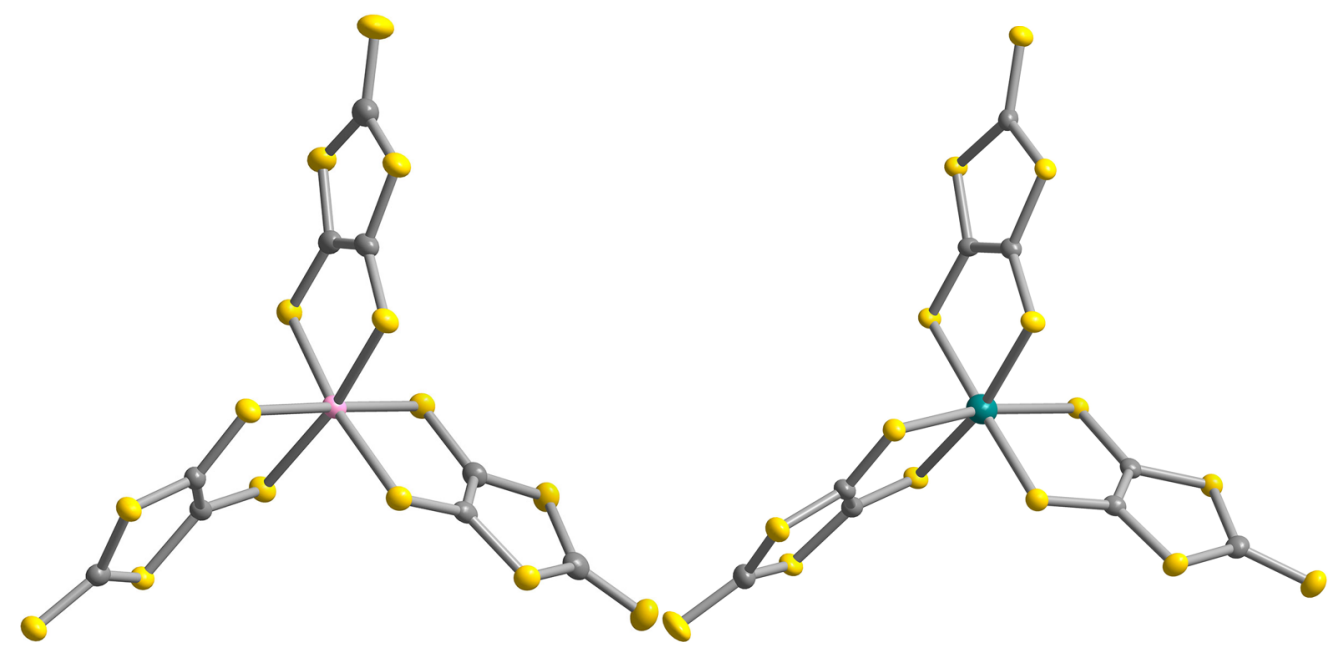

Figure S1 | Thermal ellipsoid plot of $\left[\mathrm{Cr}\left(\mathrm{C}_{3} \mathrm{~S}_{5}\right)_{3}\right]^{2-}$ and $\left[\mathrm{Ga}\left(\mathrm{C}_{3} \mathrm{~S}_{5}\right)_{3}\right]^{2-}$ as they appear in the structures of 1 (left) and 2 (right) drawn at the $50 \%$ probability level. $\mathrm{Ph}_{4} \mathrm{P}^{+}$ counterions have been removed for clarity. Yellow, grey, pink and blue-green ellipsoids correspond to sulfur, carbon, chromium and gallium atoms, respectively. 


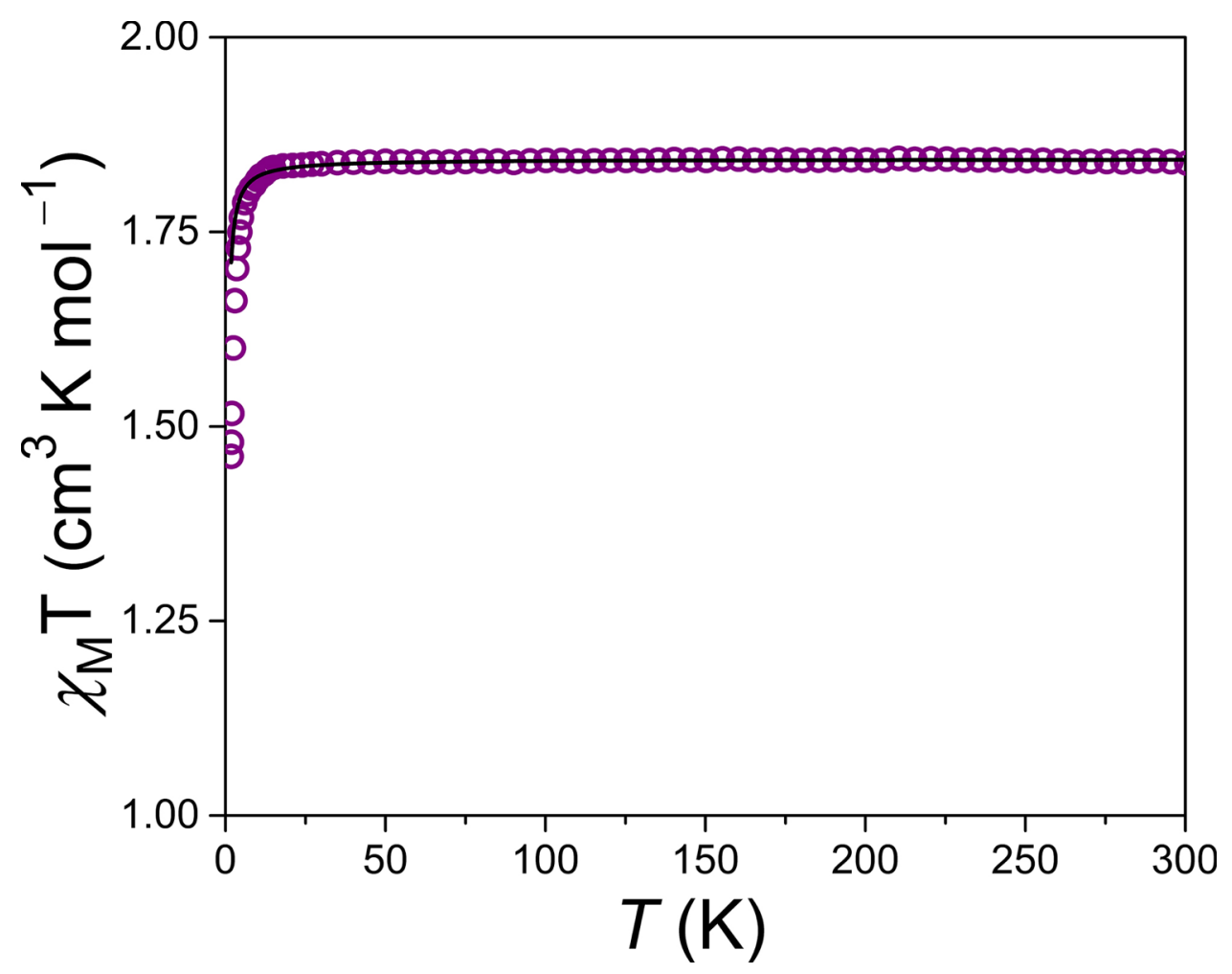

Figure S2 | Variable temperature magnetic susceptibility on 1. Data were collected from $1.8 \mathrm{~K}$ to $300 \mathrm{~K}$ under an applied de field of $1000 \mathrm{G}$. The high temperature $\chi_{\mathrm{M}} T$ value suggests a $S=3 / 2$ spin with a $g$-value of 1.96. The black line is a simulation to the data using the parameters extracted from X-band and the high-field EPR data. 


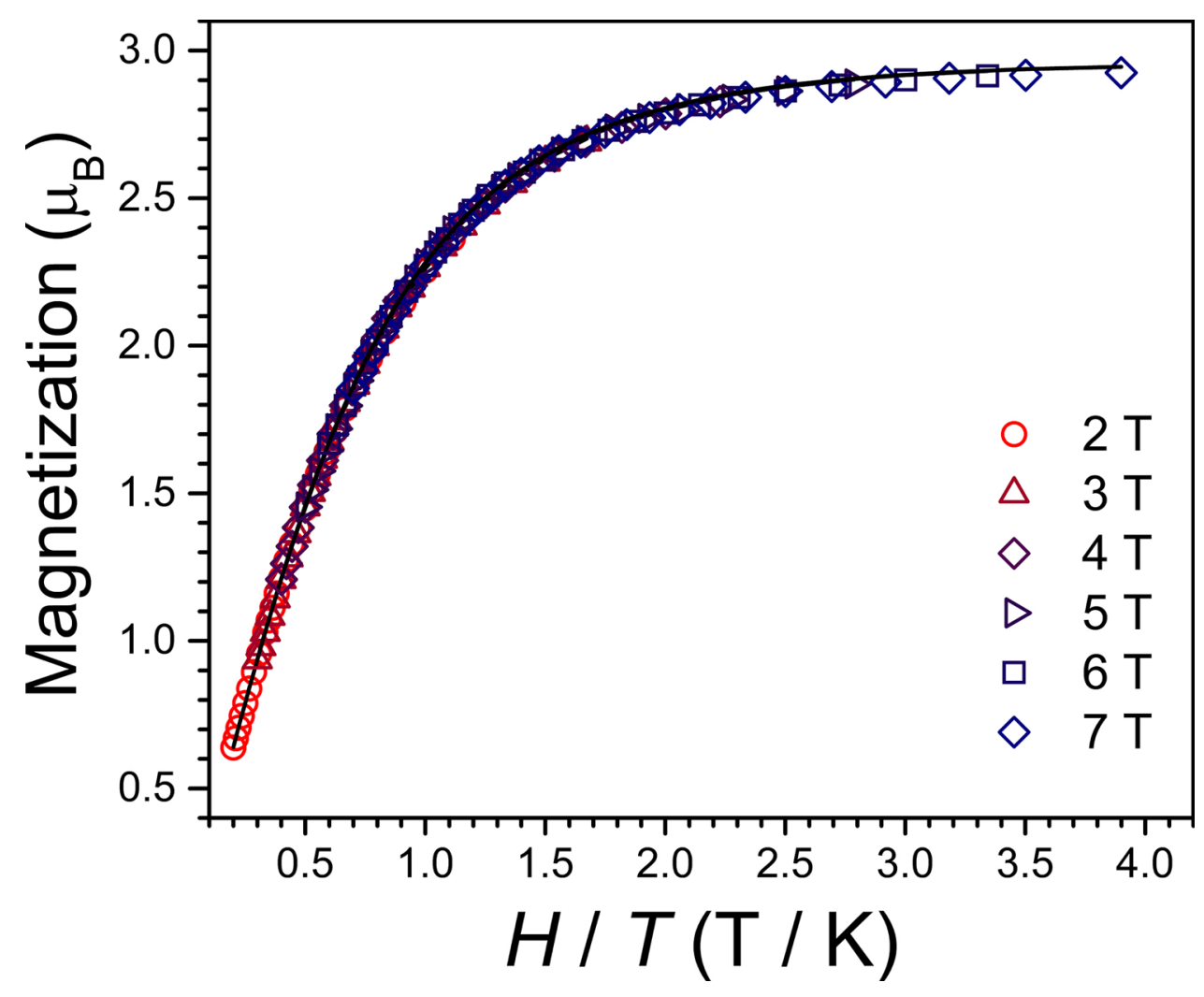

Figure S3 | Variable-temperature, variable-field magnetization of $1^{\prime}$. Variable-temperature, variable-field magnetization measurements were conducted from $1.8 \mathrm{~K}$ to $10 \mathrm{~K}$. Magnetization was measured at fields of $2 \mathrm{~T}$ through $7 \mathrm{~T}$ in $1 \mathrm{~T}$ increments. The black lines are simulations to the magnetization data using the Hamiltonian and magnetic parameters extracted from EPR. 


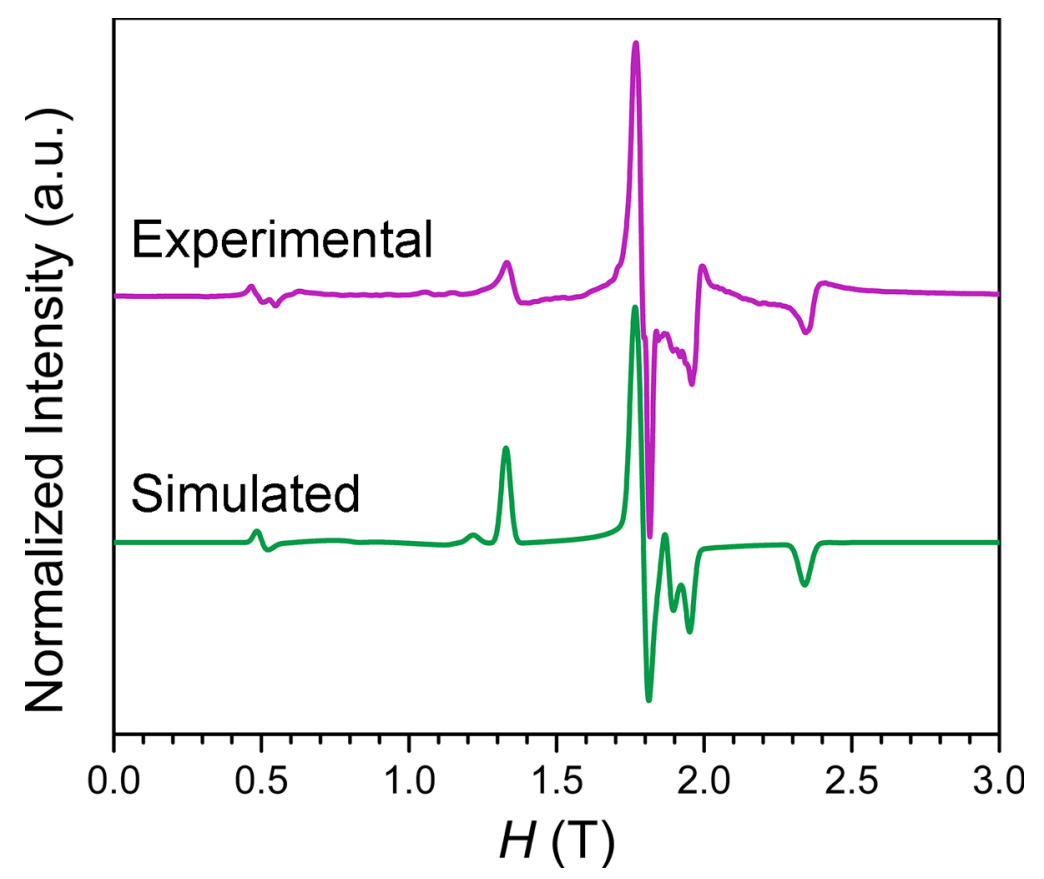

Figure S4 $51.6 \mathrm{GHz}, 5 \mathrm{~K}$ cw-EPR spectrum of 1. The purple line is the experimental data while the green line is a simulation calculated with the following parameters: $D=+0.260(7) \mathrm{cm}^{-1}, E=-0.080(2)$ $\mathrm{cm}^{-1}, g_{\mathrm{x}}=1.935(1), g_{\mathrm{y}}=2.020(1), g_{\mathrm{z}}=2.060(1)$. 

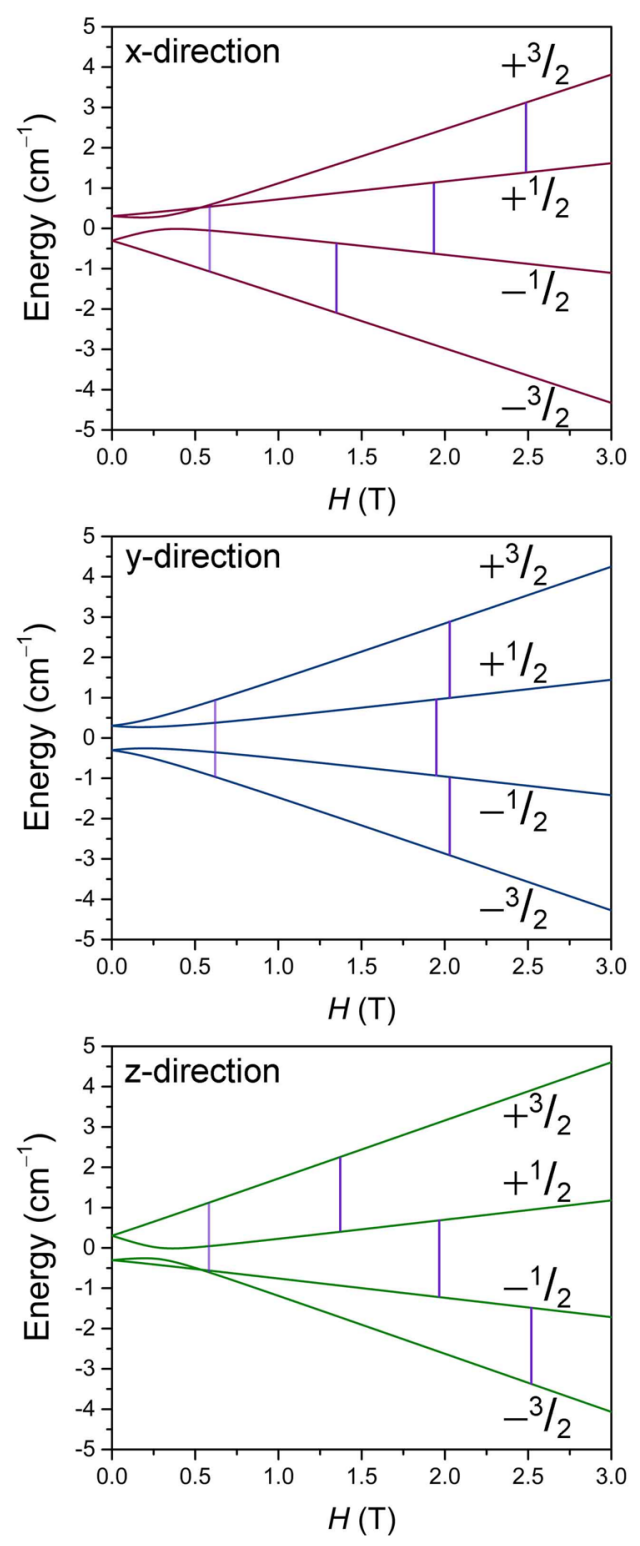

Figure S5 | Zeeman diagrams for 51.6 GHz EPR simulations. The Zeeman plots are simulated along the $\mathrm{x}-, \mathrm{y}-$, and $\mathrm{z}$-directions highlighting the transitions (purple vertical lines) observed in the spectrum. The low-field transitions $(\sim 0.6 \mathrm{~T})$ are formally forbidden yet are observed owing to a random orientation of $B_{1}$ in the spectrometer. The spin Hamiltonian parameters $g, D$, and $E$ used for these simulations are given in the main manuscript. $M_{\mathrm{S}}$ level energies here are not normalized to the ground level for clarity. $M_{S}$ level labels correspond to the labels appropriate at high fields. 


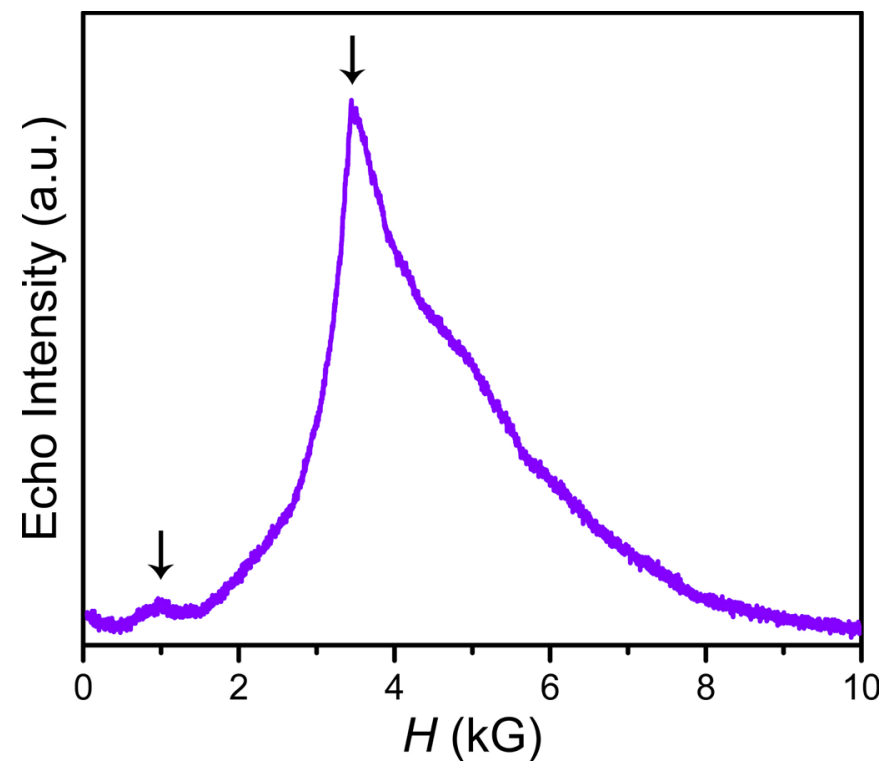

Figure S6 | Echo-detected field-swept spectrum of 1' at $5 \mathrm{~K}$. Echo-detected field-sweep spectra of complex 1' collected at X-band frequency. The data were collected between 0 and $10000 \mathrm{G}$ at $5 \mathrm{~K}$. The arrows highlight the transitions of interest at $1000 \mathrm{G}$ and $3500 \mathrm{G}$ that were further investigated as qubits. 

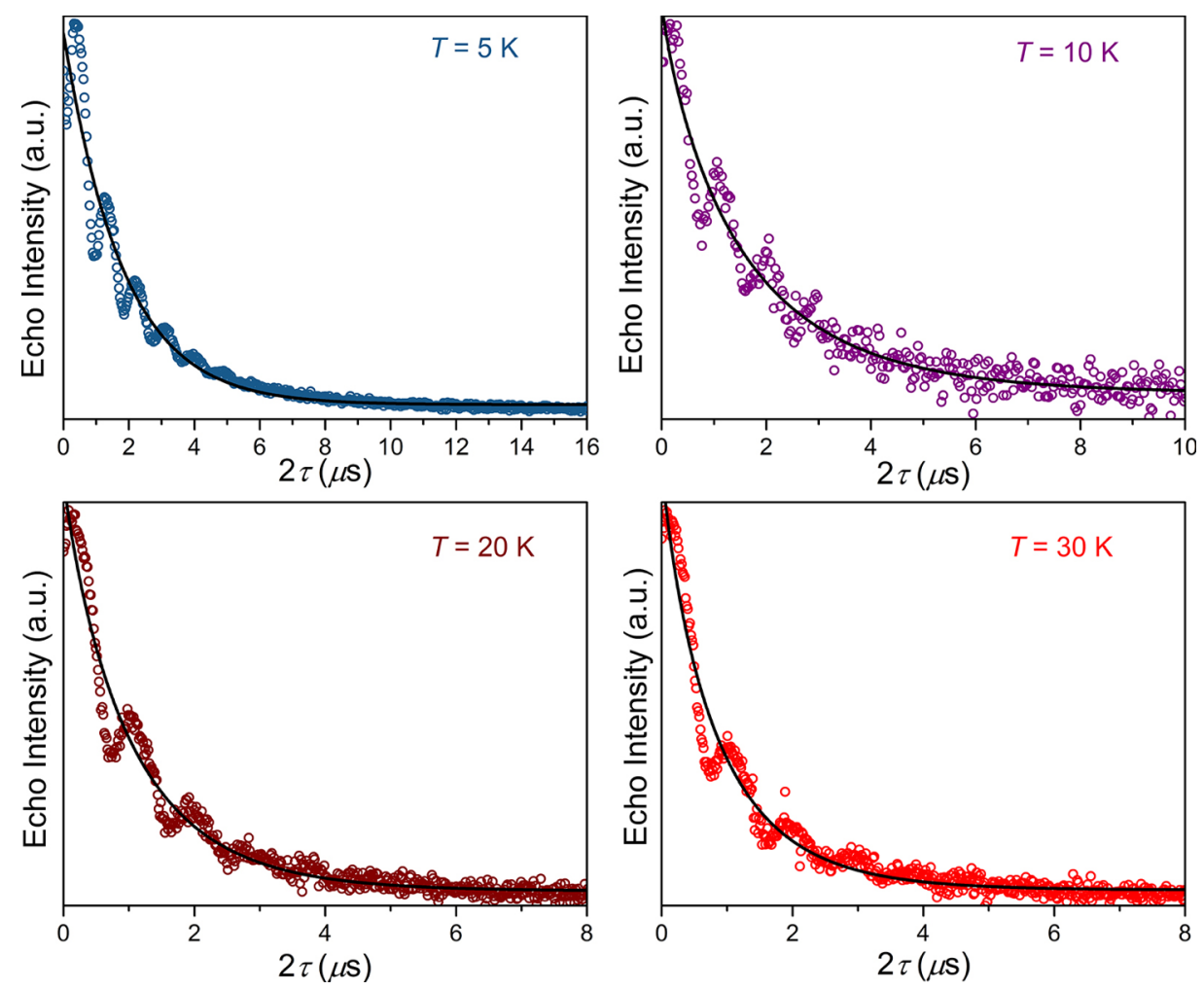

Figure S7 | Temperature dependent echo decay intensity for 1' at 3500 G Echo decay intensity (circles) and fits (black lines) using a stretched exponential function to yield $T_{2}$ times of $1.81(5), 1.52(5), 1.00(2)$ and $0.82(2) \mu$ s at $5 \mathrm{~K}, 10 \mathrm{~K}, 20 \mathrm{~K}$, and $30 \mathrm{~K}$ respectively. The oscillations observed in the decay curves correspond to ${ }^{2} \mathrm{H}$ ESEEM as illustrated in the Fast Fourier Transforms in S14. 


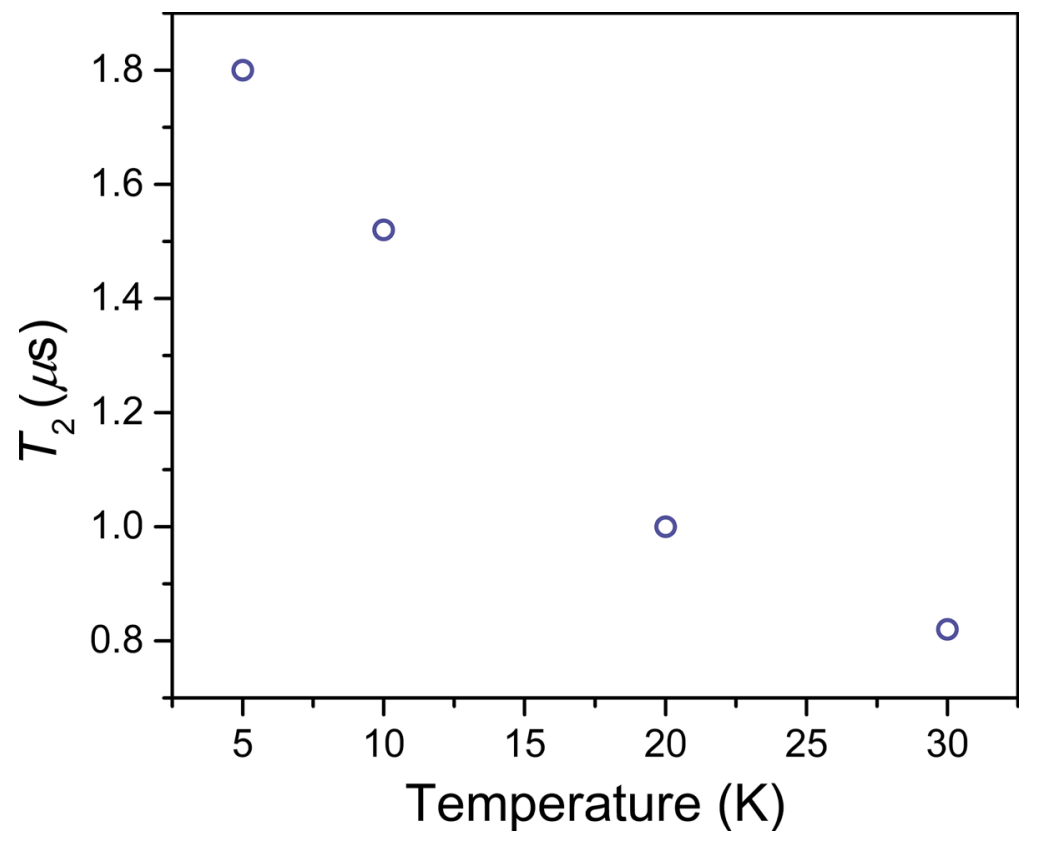

Figure S8 $\mid T_{2}$ relaxation times recorded at 5, 10, 20, and $30 \mathrm{~K}$ and $H_{\mathrm{dc}}=3500 \mathrm{G}$. The $T_{2}$ times were extracted from fitting the echo decay yielding $T_{2}$ times of 1.81(5), 1.52(5), 1.00(2) and $0.82(2) \mu$ s at $5 \mathrm{~K}, 10 \mathrm{~K}, 20 \mathrm{~K}$, and $30 \mathrm{~K}$ respectively. 

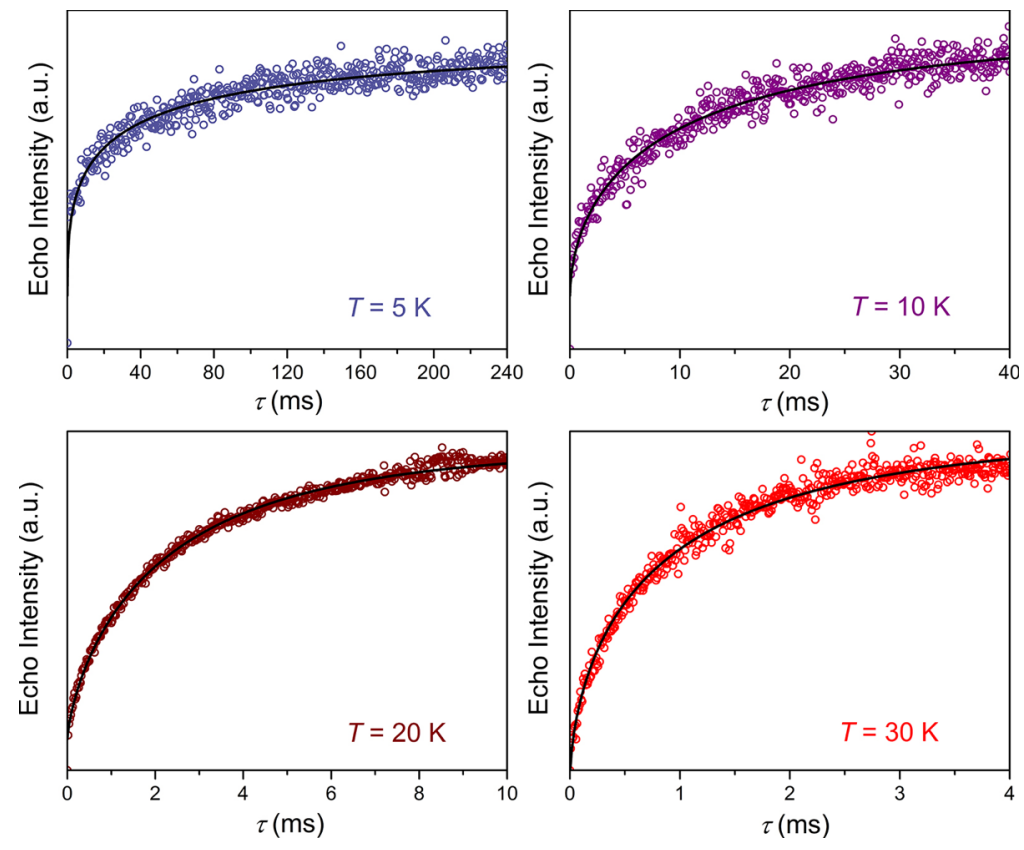

Figure S9 | Inversion-recovery data recorded at 3500 G. Inversion-recovery data recorded at $3500 \mathrm{G}$ at temperatures of $5 \mathrm{~K}, 10 \mathrm{~K}, 20 \mathrm{~K}$, and $30 \mathrm{~K}$ using a three pulse sequence. The black lines represent fits using a stretched exponential function yielding $T_{1}$ times of 29(3), $10.5(5), 2.32(2)$ and $0.87(2) \mathrm{ms}$ at $5 \mathrm{~K}, 10 \mathrm{~K}, 20 \mathrm{~K}$, and $30 \mathrm{~K}$ respectively. 


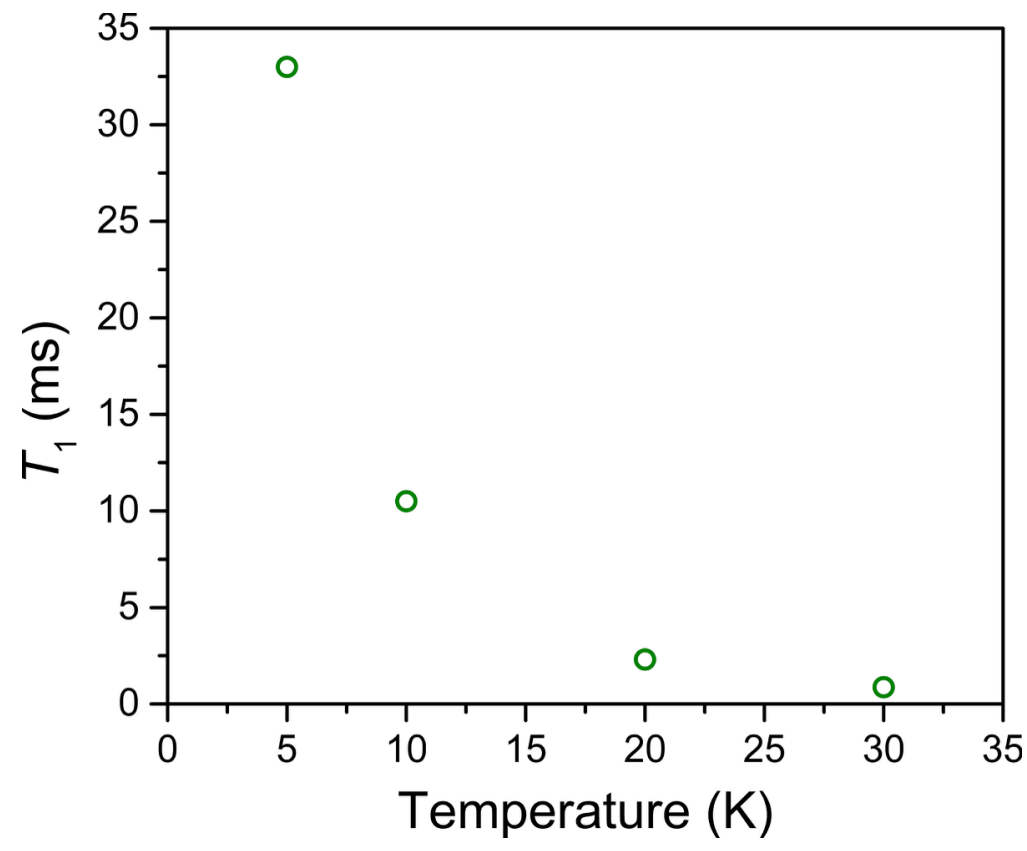

Figure S10 | $\boldsymbol{T}_{\mathbf{1}}$ relaxation time versus temperature at $3500 \mathrm{G}$. $T_{1}$ relaxation times plotted as a function of temperature illustrating the strong temperature dependence of the spin-lattice relaxation times. The error in $T_{1}$ times is smaller than the data points. 


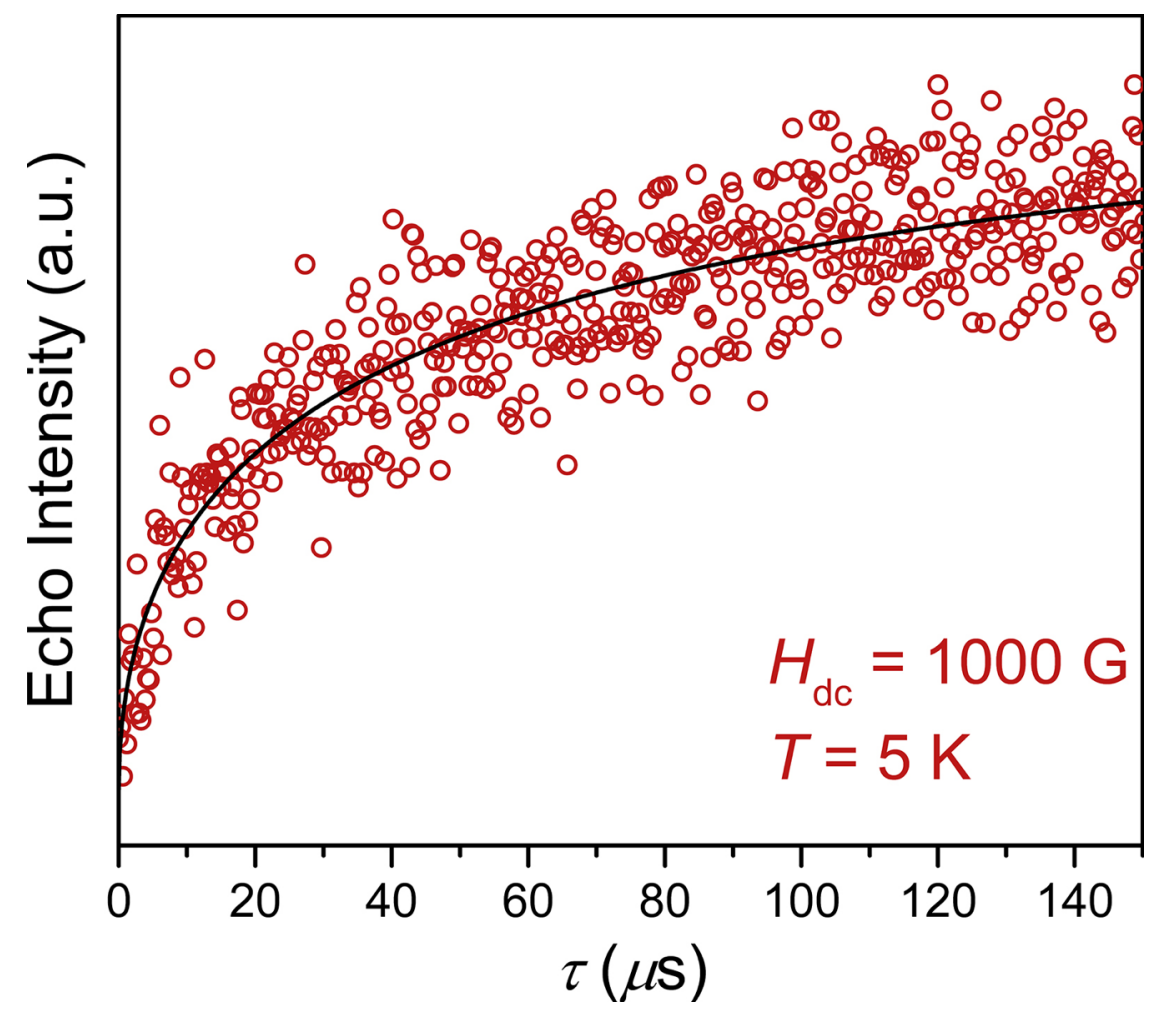

Figure S11 | Inversion-recovery data recorded at 5 K 1000 G. The black line is a fit that yields a $T_{1}$ time of $47(5) \mu \mathrm{s}$. 


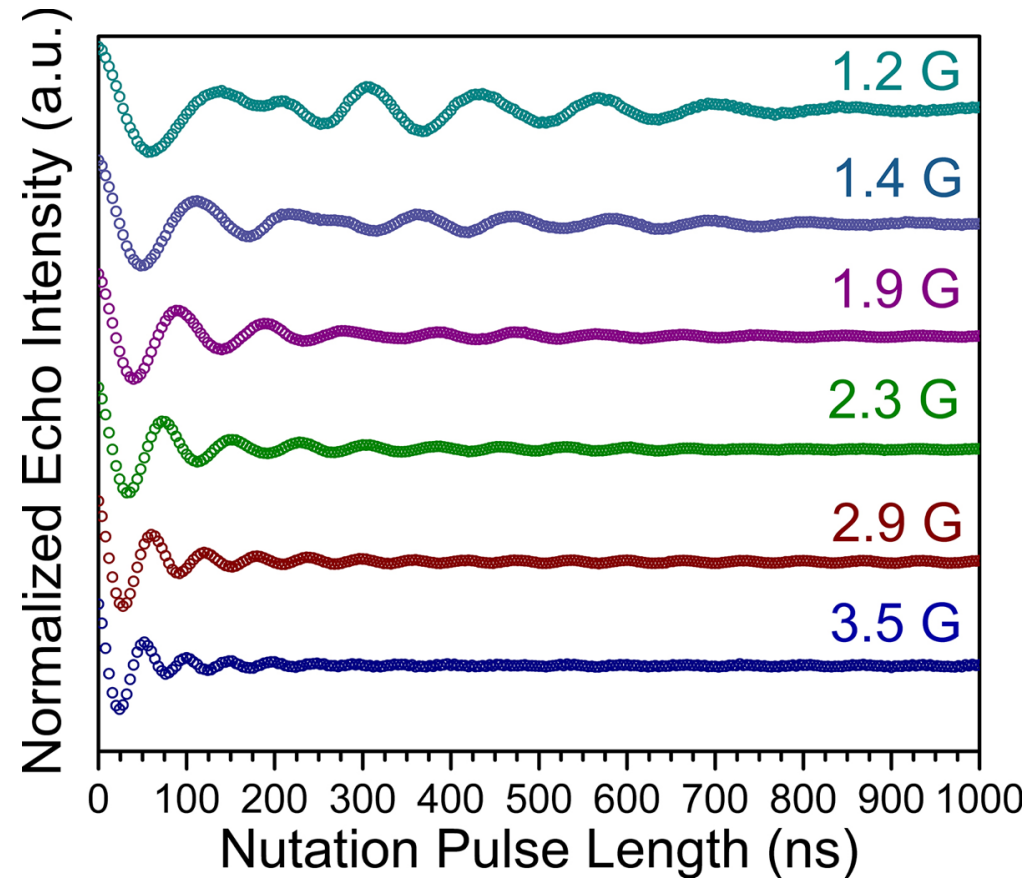

Figure S12 | Overlay of variable $\boldsymbol{B}_{1}$ nutations collected at 3500 G. Variable $B_{1}$ nutations collected on $\mathbf{1}^{\prime}$ at $5 \mathrm{~K}$ at $3500 \mathrm{G}$ under a $B_{1}$ field ranging from $1.2 \mathrm{G}$ to $3.5 \mathrm{G}$ at $5 \mathrm{~K}$. The Rabi frequency decreases with decreases $B_{1}$ values from $7.7 \mathrm{MHz}(1.2 \mathrm{G})$ to $22 \mathrm{MHz}(3.5 \mathrm{G})$. 


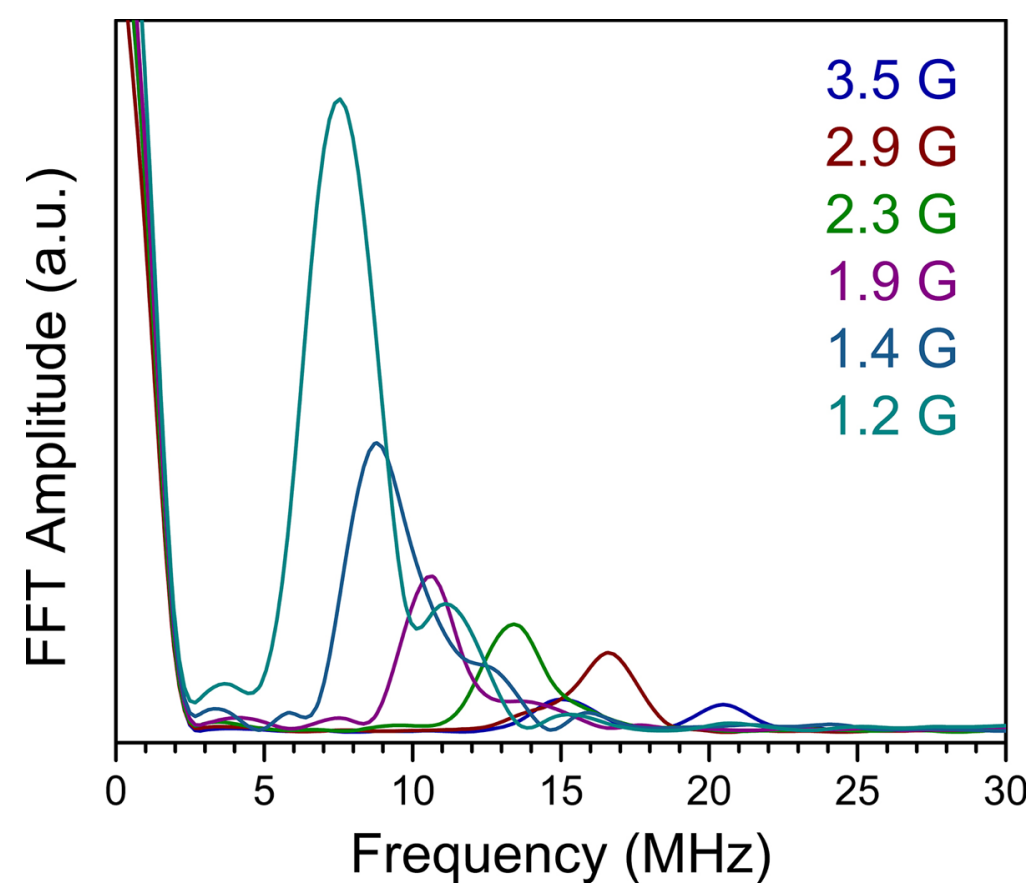

Figure S13 | Fast Fourier Transforms of the variable power nutations collected on 1' at 3500 G. Fast Fourier Transforms of the variable power nutations collected on $\mathbf{1}^{\prime}$ at $3500 \mathrm{G}$ at $5 \mathrm{~K}$ revealing the dependence of the Rabi frequency on $B_{1}$. The Rabi frequency increases from $7.7 \mathrm{MHz}$ at $1.2 \mathrm{G}$ to $22 \mathrm{MHz}$ at $3.5 \mathrm{G}$. The FFTs were performed using a Hamming window after zero filling with 1024 points. 


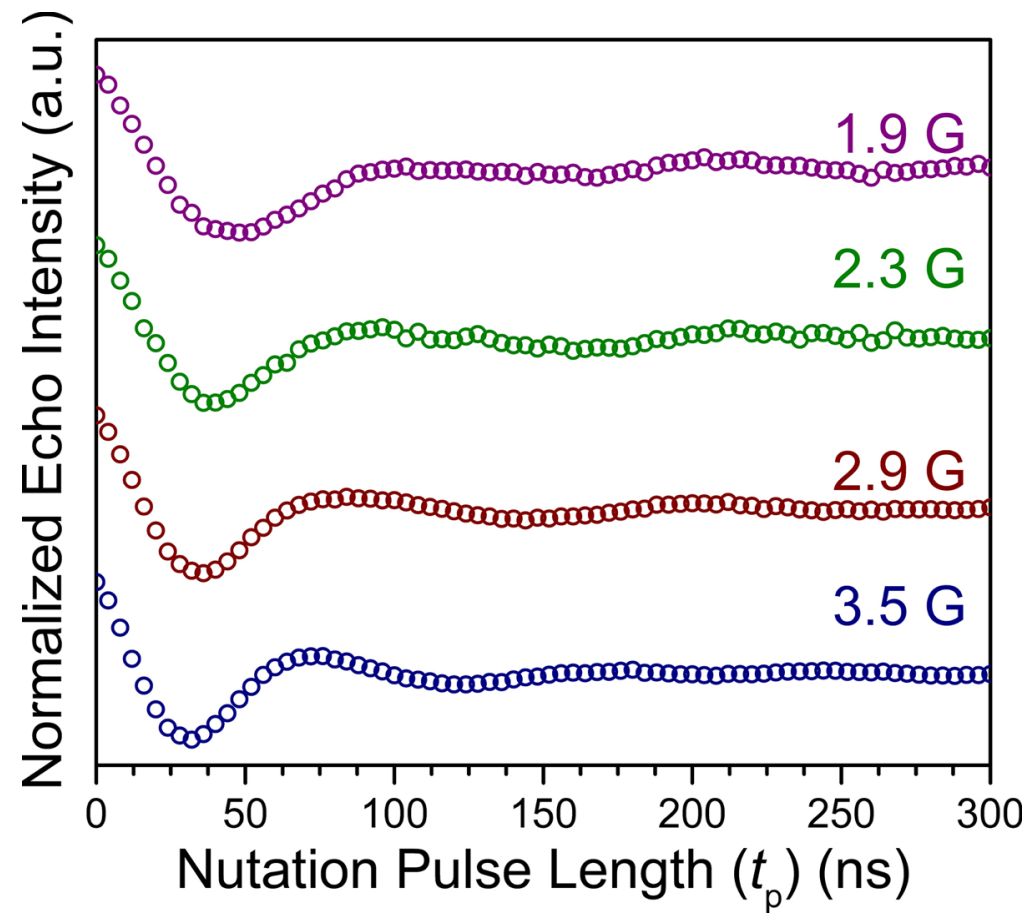

Figure S14 | Variable power nutations collected on 1' at $1000 \mathrm{G}$. Variable power nutations collected on $\mathbf{1}^{\prime}$ at $1000 \mathrm{G}$ at $B_{1}$ values ranging from $1.2 \mathrm{G}$ to $3.5 \mathrm{G}$ and $5 \mathrm{~K}$. The $\pi / 2$ pulse length necessary to manipulate the spin elongates with decreasing $B_{1}$ values from $3.5 \mathrm{G}(\pi / 2$ equal to $30 \mathrm{~ns}$ ) to $1.9 \mathrm{G} \mathrm{( \pi /2}$ equal to $46 \mathrm{~ns})$. FFTs of the nutations collected at $1000 \mathrm{G}$ were not interpretable owing to the few observable oscillations. 

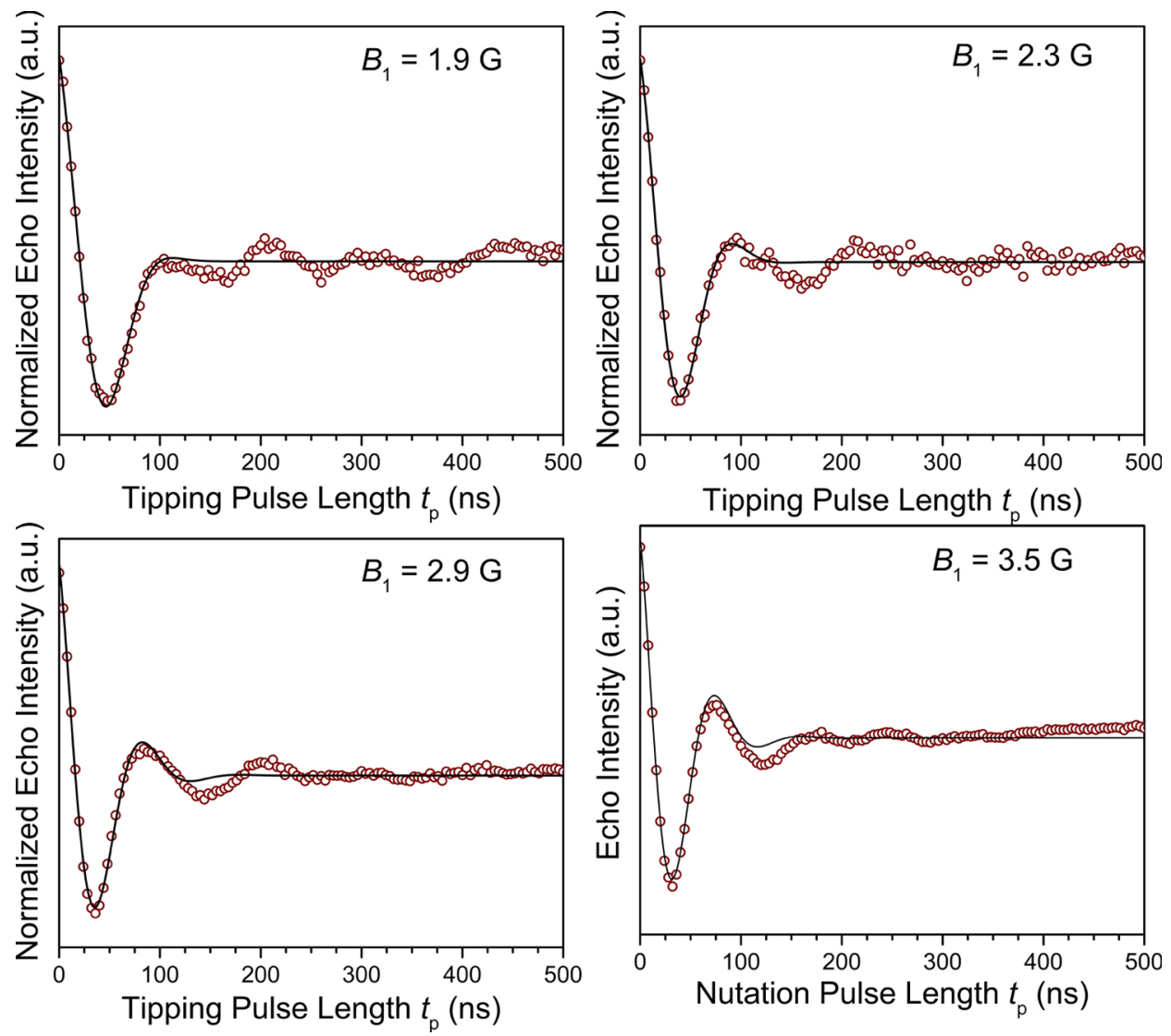

Figure S15 | Fits to the Rabi oscillations collected on $\mathbf{1}^{\prime}$ at 1000 G. Fits to the Rabi oscillations collected on $\mathbf{1}^{\prime} B_{1}$ values ranging from $1.2 \mathrm{G}$ to $3.5 \mathrm{G}$. Data were collected at $1000 \mathrm{G}$ and $5 \mathrm{~K}$. The Rabi oscillations were fit to extract the Rabi frequency due to the difficulty in extracting the Rabi frequencies from the FFTs. The fits yield Rabi frequencies of 6.3(2), 7.9(3), 9.9(1) and 11.7(2) $\mathrm{MHz}$ at $B_{1}=1.9,2.3,2.9$ and $3.5 \mathrm{G}$ respectively. See main text Figure $5 \mathrm{~b}$ for $B_{1}$ dependence of the Rabi frequency. 


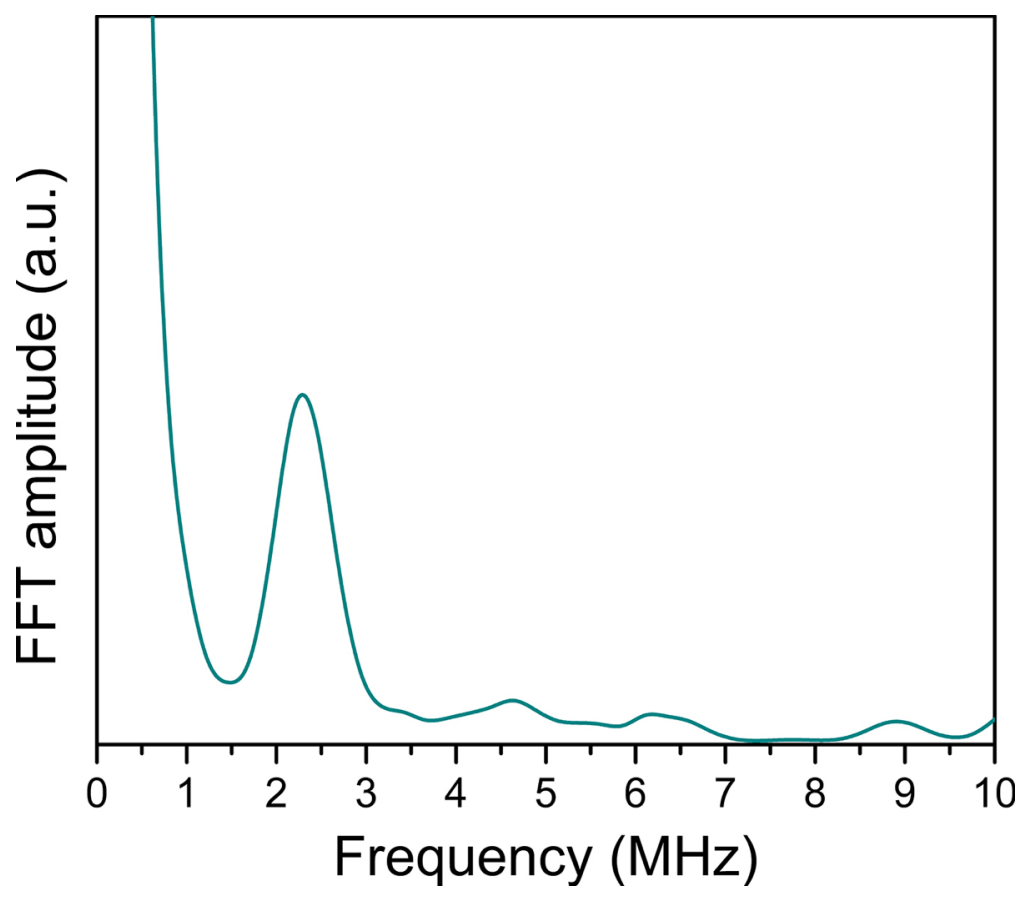

Figure S16 | Fast Fourier Transform of the $\boldsymbol{T}_{\mathbf{2}}$ decay curve collected on 1 at 3500 G. Fast-Fourier Transform (FFT) of the ESEEM modulated echo decay curve collected at $5 \mathrm{~K}$ at $3500 \mathrm{G}$. The resultant frequency corresponds to the Larmor frequency of ${ }^{2} \mathrm{H}$ at $3500 \mathrm{G}, f=2.2 \mathrm{MHz}$. The FFT was performed using a Hamming window after zero-filling with 1024 points. 


\section{References}

1. Boudjouk, P.; So, J.-H. Inorg. Synth. 2007, 29, 108-111.

2. Hansen, T. K.; Becher, J.; Jørgensen, T.; Varma, K. S.; Kheekar, R.; Cava, M. P. Org. Synth. 1996, 73, 270-273.

3. Carpenter, A. E.; Margulieux, G. W.; Millard, M. D.; Moore, C. E.; Weidemann, N.; Rheingold, A. L.; Figueroa, J. S. Angew. Chem. Int. Ed. 2012, 51, 9412-9416.

4. Marcoux, D.; Charette A. B. J. Org. Chem. 2008, 73, 590-593.

5. Bain, G. A.; Berry, J. F. J. Chem. Educ. 2008, 85, 532-536.

6. Sheldrick, G. M. SADABS, Version 2.03; Bruker Analytical X-Ray Systems, Inc.: Madison, WI, 2000.

7. Sheldrick, G. M. SHELXTL, Version 6.12; Bruker Analytical X-ray Systems, Inc.: Madison, WI, 2000.

8. Dolomanov, O. V.; Bourhis, L. J.; Gildea, R. J.; Howard, J. A. L.; Puschmann, H. J. Appl. Cryst. 2009, 42, 339-341.

9. Hassan, A. K.; Pardi, L. A.; Krzystek, J.; Sienkiewicz, A.; Goy, P.; Rohrer, M.; Brunel, L.-C. J. Magn. Reson. 2000, 142, 300-312

10. Stoll, S.; Schweiger, A. J. Magn. Reson. 2006, 178, 42-55.

11. De Raedt, H.; Barbara, B.; Miyashita, S.; Michielsen, K.; Bertaina, S.; Gambarelli, S. Phys. Rev. B 2012, 85, 014408.

12. Schweiger A.; Jeschke, G. Principles of Pulse Electron Paramagnetic Resonance; Oxford University Press: New York, 2001. 